\title{
Six Biomarkers Expressed Stably in Urinary Exosomes During All Life Stages - As the Reference Markers in Urinary Quantification
}

Man Zhang ( $\nabla$ zhangman@bjsjth.cn )

Capital Medical University

\section{Yizhao Wang}

Capital Medical University

Man Zhao

Capital Medical University

$\mathrm{Na} \mathrm{Liu}$

Capital Medical University

Cuixiu Lu

Peking University

Jun Jiang

Peking University

Tao Li

Capital Medical University

Mei Hu

Capital Medical University

\section{Research Article}

Keywords: urinary exosomes, proteomics, biomarker, RAB8A/8B

Posted Date: December 20th, 2021

DOI: https://doi.org/10.21203/rs.3.rs-1174617/v1

License: (c) (1) This work is licensed under a Creative Commons Attribution 4.0 International License. Read Full License 


\section{Abstract}

\section{Background}

Urinary extracellular exosomes (uEVs) have been identified as a novel, stable and no-invasive source of biomarkers. However, the potential clinical value of $\mathrm{uEVs}$ is limited by the lack of standard quantitative proteomics data. It is necessary to uncover ubiquitous and stable proteins of uEVs as the reference markers in urinary quantification.

\section{Samples and methods}

The samples from 210 healthy individuals (3 90 years old), were divided into seven different stages of life. The uEVs samples were identified by LC-MS/MS and data-independent acquisition (DIA) methods. Eight stably expressed UEVs proteins were obtained by bioinformatics analysis. Moreover, 42 samples were used to validate by Western blot, ELISA, and immunofluorescence.

\section{Results}

A total of 3,002 proteins and 1,393 co-expression uEVs proteins were identified by LC-MS/MS. The bioinformatics analysis showed 1,393 co-expression proteins mostly enriched in endocytosis. Eight proteins were stably expressed throughout the seven age stages $(p<0.05)$. Furthermore, RAB8A, RAB8B, Semaphorin-5A, Plexin-B2, JAMA, and STUB1 were validated by Western blot. Above all, RAB8A and RAB8B are the most stably expressed proteins in different age stages.

\section{Conclusion}

RAB8A, RAB8B, Semaphorin-5A, Plexin-B2, JAMA, and STUB1 were expressed stably proteins throughout the age stages. These six proteins might be the standard reference markers in the analysis of urine exosomal proteomics. RAB8A and RAB8B have been validated are the putative reference markers.

\section{Introduction}

Urine is the filtrate of blood, excreted in the renal tubules, contains biochemical substances and cellular components. The accumulated dynamic changes of small molecules in urine can better reflect the metabolism and pathophysiological state at a period [1,2]. Wiggins, et al. [3] recorded the presence of $\mathrm{uEVs}$ through electron microscope images for the first time. Subsequent studies analyzed the composition of urine exosomes and identified RNA, miRNA, IncRNA, and some specific proteins $[4,5]$. The stable membrane vesicle structure of exosomes triggered the exponential growth of uEVs research in the biomarkers.

The quantitative data of urine exosomes in healthy people is the basis for discovering biomarkers. Most studies on uEVs proteomics use different operating procedures and lack a unified standard [6-8]. There is also a blank in proteomic studies of human urine exosomes of all ages and genders. This study refers to 
the standard operating procedures of the Human Urine Proteome Project (HKUPP) and the European Kidney and Urine Proteomics (European Kidney and Urine Proteomics, EuroKUP) group (http://www.eurokup.org). Two hundred and ten healthy people were recruited, divided into seven age groups, and size exclusion chromatography(SEC) was used to purify urine exosomes. Mass spectrometry results showed that a total of 3,002 urine exosomal proteins and 1,393 co-expressed proteins were obtained from different age stages. We performed bioanalysis and found eight stably expressed proteins and validated six. These six stably expressed proteins are potential reference markers, and we have identified two of them.

\section{Materials And Methods}

\section{Sample Criteria}

Combined with the United Nations World Health Organization (WHO) age classification standards, the age groups were classified $A(0-6$ years old), $B(7-14$ years old), $C(15-30$ years old), $D(31-44$ years old), $E(45-59$ years old), $F(60-79$ years old), and $G(\geq 80$ years old), and each group was assigned 30 people (including 15 males and 15 females). Altogether, 210 people were recruited, and they were all of Han nationality. The physical examination illustrated that all participants had no hypertension, diabetes, cardiovascular or cerebrovascular diseases, or other diseases, and no abnormal liver or kidney function was identified. They had no history of taking medicines in the past month. With the consent of the participants, $100 \mathrm{~mL}$ of clean mid-morning urine under normal living conditions was obtained from each of them. The sample population information is shown in Table 1.

Table 1 Basic information of experimental subjects 
Group Sex $\quad$ Age $\quad$ Total Protein

Healthy $(210$ person)

\begin{tabular}{|c|c|c|c|}
\hline \multirow[t]{3}{*}{ A $0-6 Y$} & Male 15 person & $4.53 \pm 0.88$ & $0.53 \pm 0.07$ \\
\hline & $\begin{array}{l}\text { Female } 15 \\
\text { person }\end{array}$ & $4.73 \pm 1.00$ & $0.45 \pm 0.08$ \\
\hline & Total & $4.63 \pm 0.95$ & $0.49 \pm 0.09$ \\
\hline \multirow[t]{3}{*}{ B 7-14Y } & Male 15 person & $9.40 \pm 1.62$ & $0.43 \pm 0.10$ \\
\hline & $\begin{array}{l}\text { Female } 15 \\
\text { person }\end{array}$ & $8.33 \pm 1.53$ & $0.47 \pm 0.06$ \\
\hline & Total & $8.87 \pm 1.67$ & $0.45 \pm 0.09$ \\
\hline \multirow{3}{*}{$\begin{array}{l}\text { C 15- } \\
\text { 30Y }\end{array}$} & Male 15 person & $25.67 \pm 2.47$ & $0.41 \pm 0.13$ \\
\hline & $\begin{array}{l}\text { Female } 15 \\
\text { person }\end{array}$ & $27.60 \pm 1.25$ & $0.40 \pm 0.17$ \\
\hline & Total & $26.63 \pm 2.18$ & $0.40 \pm 0.15$ \\
\hline \multirow{3}{*}{$\begin{array}{l}\text { D 31- } \\
44 Y\end{array}$} & Male 15 person & $37.07 \pm 3.36$ & $0.43 \pm 0.10$ \\
\hline & $\begin{array}{l}\text { Female } 15 \\
\text { person }\end{array}$ & $35.67 \pm 3.38$ & $0.50 \pm 0.14$ \\
\hline & Total & $36.37 \pm 3.44$ & $0.47 \pm 0.13$ \\
\hline \multirow[t]{3}{*}{ E 45-59Y } & Male 15 person & $52.53 \pm 3.59$ & $0.47 \pm 0.12$ \\
\hline & $\begin{array}{l}\text { Female } 15 \\
\text { person }\end{array}$ & $51.00 \pm 3.35$ & $0.46 \pm 0.10$ \\
\hline & Total & $51.77 \pm 3.56$ & $0.47 \pm 0.11$ \\
\hline \multirow[t]{3}{*}{ F 60-79Y } & Male 15 person & $69.67 \pm 5.25$ & $0.44 \pm 0.15$ \\
\hline & $\begin{array}{l}\text { Female } 15 \\
\text { person }\end{array}$ & $69.40 \pm 4.74$ & $0.45 \pm 0.19$ \\
\hline & Total & $69.53 \pm 5.00$ & $0.44 \pm 0.17$ \\
\hline \multirow[t]{3}{*}{$G \geq 80 Y$} & Male 15 person & $83.73 \pm 2.91$ & $0.48 \pm 0.14$ \\
\hline & $\begin{array}{l}\text { Female } 15 \\
\text { person }\end{array}$ & $83.07 \pm 7.54$ & $0.42 \pm 0.12$ \\
\hline & Total & $83.40 \pm 5.72$ & $0.45 \pm 0.13$ \\
\hline
\end{tabular}

\section{Isolation and Preservation of Urinary Exosomes}

Regarding the standard operating procedures of HKUPP and EuroKUP (http://www.eurokup.org), the obtained urine samples were immediately placed in a refrigerator at $4{ }^{\circ} \mathrm{C}$, and the urine was processed 
within 2 hours. First, a urine sample was processed at $1500 \mathrm{~g} \times 10$ minutes at $4{ }^{\circ} \mathrm{C}$ and then $5000 \mathrm{~g} \times 30$ minutes to remove the cells. Second, sterilization and cell debris were filtered with a $0.22 \mu \mathrm{m}$ filter (Millipore, SLGVR33RB). Third, the urine was concentrated through an ultrafiltration tube (Millipore, UFC910024). Finally, the size exclusion method (Izon Science Ltd, qEV10/35 nm) was used to extract the exosomes in the concentrated urine samples, which had been resuspended in PBS and stored directly at $-80^{\circ} \mathrm{C}$.

\section{Identification of Urinary Exosomes}

\section{TEM}

Five microliters of urine exosome samples were dropped on the copper mesh. After incubation for 5 minutes at room temperature, the excess liquid was absorbed with absorbent paper from one side. Then, a drop of $2 \%$ uranyl acetate was put on the sample and incubated at room temperature for 1 minute, and then, the surface liquid from one side was absorbed by the absorbent paper. After a 20-minute drying process, the morphology of the urine exosomes was observed under a microscope (Tecnai G2 Spirit BioTwin, $\mathrm{FEI})$.

\section{NTA}

The sample was diluted with prechilled $1 \times$ PBS to a suitable concentration and directly used for NTA (ZetaVIEW S/N 17-310, PARTICLE METRIX) detection (ZetaView 8.04.02) of the urine exosomal particle size.

\section{Western Blot}

Urine exosome samples were lysed with RIPA strong lysis buffer containing PMSF. Then, the sample with the determined protein concentration was loaded on a $15 \%$ sodium dodecyl sulfate- polyacrylamide gel. Next, $65 \mathrm{~V}$ to $100 \mathrm{~V}$ was used for electrophoresis, and then the membrane was transferred with a rapid transfer system (Bio-Rad, TURBO). Furthermore, a 5\% blocking solution with TBST and skim milk powder was made and placed on a shaker at room temperature for 2 hours or at $4{ }^{\circ} \mathrm{C}$ overnight. Anti-CD9(Abcam, ab236630), Anti-CD63 (Abcam, ab271286), Anti-CD81 (Thermo, MA1-10290), Anti-RAB8A (Abcam, ab188574), Anti-RAB8B (Abcam, ab222017), Anti-Plexin B2/MM1 (Abcam, ab193355), Anti-Semaphorin 5A (Bioss, bs-20430R), Anti-Junctional adhesion molecule A (Abcam, ab269948) and Anti-STUB1/CHIP (ab134064) antibodies were then diluted at a ratio of 1:1000, followed by incubation in a refrigerator at 4 ${ }^{\circ} \mathrm{C}$. After washing the membrane, a 1:2000 diluted secondary antibody was incubated for 2 hours at room temperature. Then, the membrane was rewashed with TBST and poured with chemiluminescent HRP solution (Millipore, WBKLS0500) for exposure.

\section{Enzyme-linked immunosorbent assay}


Took the standard solution to make a standard curve, added $100 \mu \mathrm{L}$ sample to be tested to the sample well, sealed the plate with a sealing film, and incubated at $37^{\circ} \mathrm{C}$ for 90 minutes. Next, discard the solution in the plate, washing the plate two times with wash buffer. Added $100 \mu \mathrm{L}$ of biotin-labeled RAB8A (FineTest, EH1615) and RAB8B (FineTest, EH11620) antibody working solution into the above wells, covered the plate, and incubated at $37^{\circ} \mathrm{C}$ for 60 minutes. Remove the cover and washing the plate three times with wash buffer. Added 100ul of HRP-streptavidin conjugate SABC working solution into each well, cover the plate, and incubate at $37^{\circ} \mathrm{C}$ for 30 minutes. After washing, added $90 \mu \mathrm{L}$ TMB substrate and $50 \mu \mathrm{L}$ stop solution into each well. The OD value was measured at $450 \mathrm{~nm}$ and calculated the concentration according to the standard curve.

\section{Immunofluorescence}

The suspension containing EVs was added to a shaker box, centrifuged at $1500 \mathrm{r} / \mathrm{min} \times 7 \mathrm{~min}$, permeabilized with $0.3 \%$ Triton X-100 for $10 \mathrm{~min}$, and then blocked with $2 \%$ BSA (prepared in PBS) at room temperature for $30 \mathrm{~min}$. The specific primary antibody (prepared in $2 \% \mathrm{BSA}$, dilution ratio 1:2000) and fluorescein-labeled mouse secondary antibody (Abcam, ab150077) were incubated in a humid box at $37^{\circ} \mathrm{C}$ for 30 minutes and observed under an upright fluorescent microscope (EUROStar III Plus).

\section{LC-MS/MS}

\section{Protein Isolation}

The samples were mixed evenly, and then the urea particles were added to obtain a mixed sample suspension with a final urea concentration of $8 \mathrm{M}$. The sample was shaken until the urea particles were fully dissolved. Then, the sample was concentrated in an ultrafiltration tube. Ten microliters were maintained for Bradford protein quantification, and the remaining sample aliquots were kept at $-80^{\circ} \mathrm{C}$.

\section{Enzymatic Desalination}

Then, $100 \mu \mathrm{g}$ of sample protein was added to $10 \mathrm{mM} \mathrm{DTT}$ and reduced to $56^{\circ} \mathrm{C}$ for 1 hour. Then, it was alkylated with iodoacetamide for 1 hour in a dark room at room temperature. The protein was digested with trypsin at a ratio of $1: 50$ and $37^{\circ} \mathrm{C}$ overnight, desalted with a $\mathrm{C} 18$ cartridge to remove high urea, and dried by vacuum centrifugation.

\section{Library construction and mass spectrometry data acquisition in DIA mode}

A Q Exactive HF-X mass spectrometer and Nanospray Flex ${ }^{\mathrm{TM}}(\mathrm{NSI})$ ion source were employed. The ion spray voltage was $2.4 \mathrm{kV}$, and the temperature of the ion transfer tube was $275^{\circ} \mathrm{C}$. Data-dependent acquisition mode was performed, with a scanning range of 350-1500 m/z to construct the library. Mass spectrometry data were obtained by data-independent acquisition (DIA) mode, with a spectrum scanning range of $\mathrm{m} / \mathrm{z}$ 350-1500.

\section{Statistics and Analysis}




\section{Bioinformatics Analysis}

This experiment employed the Homo sapiens database. Data analysis and visualization of DDA and DIA data were performed using the Proteome Discoverer 2.4 (PD 2.4, Thermo) platform, Biognosys Spectronaut 13 version, and R statistical framework. The original DDA-MS file was analyzed with PD software (version 2.4). The peak list was also searched against the protein database. Clusters of Orthologous Groups (COG) were performed for homology classification. The protein database was used for Gene Ontology (GO) to perform the statistical analysis of cell components, molecular functions, and biological processes (CC). The identified proteins data from each group of samples were uploaded to the Kyoto Encyclopedia of Genes and Genomes (KEGG) (http://www.genome.jp/kegg) website to obtain and analyze all the map results from all channels.

\section{Statistical Analysis}

All experiments were performed three times. All values are expressed as the mean \pm standard deviation. Here, we took a 1.5-fold change as a cutoff for differentially expressed proteins, and $P<0.05$ was considered statistically significant. For the Enzyme-linked immunosorbent assay, tests were completed by R3.6.3 software. Due to the Shapiro-Wilk normality test, some groups did not meet the normal distribution. Therefore, to ensure the uniformity of all tests, the Kruskal-Wallis test was used for the different analyses for the simultaneous comparison of multiple groups. For pairwise comparisons, Wilcoxon rank-sum test was used for different analyses.

\section{Results}

\section{Exosomes obtained from urine meet the requirements of ISEV}

\section{NTA}

Nanoparticle tracking analysis (NTA) detected sample sizes ranging from $30 \mathrm{~nm}$ to $200 \mathrm{~nm}$. The major peak of the diameter particle was identified as $109.7 \mathrm{~nm}$, accounting for $96.6 \%$, and the median (X50) was $130.4 \mathrm{~nm}$, which met the standard overall (Figure 2a).

\section{Enriched Protein}

Western blot showed that CD9, CD63, and CD81 were strongly expressed in purified urinary exosomes (Figure 2b).

\section{TEM}

A clear vesicle structure could be seen under a transmission electron microscope (TEM). The particle size of the vesicle met the detection standard of exosomes (Figure 2c).

\section{All age stages shared 1,393 proteins}


A total of 3,002 proteins were collected in the A-G groups of urine exosomes. Among 3,002 proteins, 1,393 proteins were shared by A-G groups. Boxplots and heat maps were used for cluster analysis, and the results showed that the urinary exosome proteomics data obtained by the LC-MS/MS method were reliable and could be used for more analysis.

COG

The 1,393 proteins were assigned to 25 entries (one was Function unknown). 223 proteins were involved in the signal transduction mechanism, accounting for 16.7\%; 209 proteins were involved in general function prediction, and 161 proteins were involved in posttranslational modification, protein turnover, and chaperones.

\section{GO and KEGG}

GO analysis is performed on urine exosome co-expressed proteins from a global perspective. The functional role of urine exosome proteins is determined by GO analysis, and the attributable protein entries of biological processes, cell components, and molecular functions are obtained. The GO classification system shows that these proteins can be classified according to their functional properties. In the biological process (BP), the number of proteins involved in endocytosis is the largest, followed by the actin filament-based process and immune effector process; the top three in cell component (CC) are lytic vacuole, secretory granule lumen, and side of the membrane. The protein is concentrated in the cell adhesion molecule binding, calcium ion binding, and protein domain-specific binding in molecular function (MF). Corresponding to the above, KEGG analysis showed that the protein was enriched in endocytosis, phagosome, lysosome, and other pathways.

\section{RAB8A, RAB8B, Semaphorin-5A, Plexin B2, STUB1, JAMA, Syndecan-2, and LANCL1 of uEVs have stably expressed at all ages}

Analysis of the 1,393 co-expressed proteins in quantification, we found that RAB8A, RAB8B, Semaphorin5A, Plexin B2, STUB1, JAMA, Syndecan-2, and LANCL1 were constantly expressed among the age groups and genders. Among them, RAB8A, RAB8B, Semaphorin-5A, Plexin B2, STUB1, and JAMA were verified by Western blot.

\section{The validation of RAB8A and RAB8B}

Enzyme-linked immunosorbent assays and immunofluorescence verified the expression of RAB8A/RAB8B. As shown in Figure 7 a, the quantification level of biomarkers universal used in exosomes are higher than RAB8A/RAB8B. RAB8A and RAB8B are more stable than those biomarkers in different age groups and genders. Moreover, RAB8A/8B ELISA kits were used to establish standard curves with the standard solution, with the $\mathrm{R}^{2}$ values of 0.9958 and 0.9932 , respectively. The formula calculated the sample concentration. The median value of RAB8A concentration was $1.48 \mathrm{ng} / \mathrm{mL}$, the first quartile value Q1 is $1.18 \mathrm{ng} / \mathrm{mL}$, the third quartile value Q3 is $1.73 \mathrm{ng} / \mathrm{mL}$. The median value of RAB8B 
concentration was $132.45 \mathrm{pg} / \mathrm{mL}$, the first quartile value Q1 is $108.46 \mathrm{pg} / \mathrm{mL}$, the third quartile value Q3 is $144.39 \mathrm{pg} / \mathrm{mL}$. After staining, RAB8A and RAB8B were visible under the fluorescence microscope.

\section{Discussion}

In recent years, urine has become the second most significant biological fluid used for clinical diagnosis after blood due to its comprehensive advantages [8-10]. The advent of the proteomics era has dramatically promoted the ability to obtain protein information in basic and clinical research. However, many challenges exist in research about urine protein biomarkers, such as low protein abundance, salt presence, fluctuating expression, and high variability between and within individuals. The above points make the downstream research more challenging [11]. The proteomics of exosomes has stable and credible characteristics. Moreover, clarifying the protein composition of healthy human urine exosomes is the basis for discovering urinary reference markers [12].

This study followed the standards set by HKUPP, EuroKUP, and ISEV (International Society for Extracellular Vesicles) to screen the samples strictly $[13,14]$, isolated higher purity uEVs by size exclusion chromatography without expensive equipment. The information with better reproducibility, stability, and coverage was obtained by DIA approach[15]. Exosomes are generally considered to play an important role in cell communication and transportation in pathophysiological processes, including development, immunity, tissue homeostasis, and cancer. [16-18]. The COG analysis of this study shows that the number of proteins involved in signal transduction mechanisms in urinary exosomes is the largest, accounting for $16.7 \%$, which fully supports the above view. We obtained and verified the constant expression of RAB8A, RAB8B, Semaphorin-5A, Plexin B2, STUB1, and JAMA, the potential quantitative reference markers of human urinary exosomes. It is undeniable that the four transmembrane proteins $C D 9, C D 63, C D 81$, and TSG101 are widely used to identify exosomes [19]. However, we measure whether a protein is suitable as the marker only from the expression level, then the abovementioned universal biomarkers are ranked 86 , 456,112 , and 209 in the urine exosomal protein identified. Therefore, measuring the expression level alone is not comprehensive, and stable expression is also a key feature of markers. The verification results show that RAB8A, RAB8B, Semaphorin-5A, Plexin B2, STUB1, and JAMA are stable proteins in uEVs of different age stages and genders. Considering the stable expression characteristics of markers, we have reason to believe that these six proteins are suitable as potential reference markers for urinary exosomes. The reasons why these proteins can be stably expressed and become the reference markers in urine exosomes are considered as follows.

Firstly, RAB8A and RAB8B play a significant role in signal transduction and vesicle transport as members of Rab GTPases [20,21]. It is known that Rab GTPases constitute the largest group of small GTPases, with a total of approximately 70 members [22]. As the critical regulatory factor in forming transport vesicles and membrane fusion, Rabs circulate between the inactive form combined with guanosine diphosphate and the active form combined with guanosine triphosphate [23]. According to our results, 37 Rab GTPases were identified. Among them, 28 were defined as extracellular transport, secretion, and vesicle transport, and 12 were defined as signal transduction in the COG analysis. Some Rab GTPases 
are extracellular transport, secretion, vesicle transport, and signal transduction, showing the complex connection between signal transduction and membrane transport. Secondly, Rab GTPases are essential for neuronal function [24]. Embryo development is a highly complex process requiring close coordination between cells, which relies on membrane transport to properly handle receptors, transporters, and adhesion molecules [25]. Researchers believe that signal transduction and membrane transport can finetune the homeostasis of cells and the body, membrane transport defects are a sign of neurodegeneration, and Rab GTPases are precisely the critical regulators of signal transduction and membrane transport [21]. The changes in Rab GTPases are related to almost all neuronal activity in health [20]. Although the specific molecular role of Rab GTPases in the development process is still unclear, many studies have emphasized the necessity of Rab GTPases in the development of multiple mammalian embryos [25]. In multiple experiments, the mice that knocked out the Rab proteins died at the embryonic stage or shortly after birth [26-29]. The above shows that Rab GTPases play an essential and indispensable role in embryonic development. Therefore, we speculate that this is one of the possible reasons for the stable expression of RAB8A and RAB8B in human urinary exosomes. Thirdly, we also believe that the stable expression of RAB8A and RAB8B in human urinary exosomes is related to the growth of cilia and the process of autophagy. It is worth noting that defects in primary cilia function are related to increasing human development and degenerative diseases, which affect the functions of many organs of the body, collectively referred to as ciliary disease [30]. Primary cilia perceive various environmental signals in the extracellular environment. RAB8 acts as a surface receptor on the cilia membrane to transmit the sensed signals to the cell [31,32], becoming an essential part of the cilia growth process [33]. In addition, autophagy is a catabolic process that plays an essential role in homeostasis by providing energy to recover cellular components. Rab proteins are involved in all stages of autophagy. RAB7, RAB8B, and RAB24 play a crucial role in the maturation of autophagosomes $[34,35]$. RAB8A and RAB25 are also involved in autophagy. The protein complex composed of C9ORF72, WDR41, and SMCR8 can be used as the GTP exchange factors (GEFs) of RAB8A and RAB39B to regulate GTP/GDP exchange, control autophagic flux, and then participate in the maintenance of the body's environmental homeostasis [36]. The stable existence of RAB8A and RAB8B maintains the regular operation, and they are vital proteins in the development process. After a comprehensive analysis, we believe that RAB8A and RAB8B are involved in signal transduction, vesicle transport, neuronal function, cilia growth, and autophagy processes, further participating in the development of the body and maintaining the regular operation of the body functions.

Similar to RAB8A/B, Semaphorin-5A and Plexin B2 play a vital role in forming axons and other neural development processes [37,38]. In addition, the adhesion molecule A and STUB1 play an essential role in forming tight junctions [39] and regulate the quality of peroxisomes, respectively [40]. These give us reasons to believe that Semaphorin-5A, Plexin B2, STUB1, and JAMA are stably expressed throughout the age stages.

\section{Conclusion}


Through rigorous experimental design and the implementation of reasonable experimental programs, providing objective and credible human urinary exosomal protein profile data. By bioinformatics analysis, it is learned that eight proteins are stably expressed of all ages. Further experimental results showed that RAB8A, RAB8B, Semaphorin-5A, Plexin B2, STUB1, and JAMA are the potential reference markers of human urine exosomal. The screening and verification of specific disease-related biomarkers require more downstream experiments to complete and supplement.

\section{Abbreviations}

LC-MS/MS: liquid chromatography-tandem mass spectrometry DIA: data-independent acquisition Rab8A: Ras-related protein Rab-8A Rab8B: Ras-related protein Rab-8B Junctional adhesion molecule A: JAMA E3 ubiquitin-protein ligase CHIP: STUB1 EVs: extracellular vesicles THP: Tamm Horsfall protein HKUPP: Human Urine Proteome Project EuroKUP: European Kidney and Urine Proteomics SEC: size exclusion chromatography BP: biological process CC: cell component MF: molecular function SELDI-TOF MS: laser desorption/ionization time-of-flight mass spectrometry CE-MS: capillary electrophoresis mass spectrometry.

\section{Declarations}

\section{Acknowledgements}

We would like to give our sincere gratitude to the reviewers for their constructive comments.

\section{Authors' contributions}

Man Zhang designed the research plan. This study was mainly completed by Yizhao Wang with the assistance of Man Zhao, Na Liu, Cuixiu Lu, Jun Jiang, Tao Li, and Mei Hu. All authors read and approved the final manuscript.

\section{Funding}

This work was supported by Beijing Key Clinical Specialty Program grant number: 2020ZDZK2 , Capital Health Research and Development of Special grant number: 2020-A16 and Beijing Municipal Science and Technology Project.

\section{Availability of data and material}

The raw data supporting the conclusions of this manuscript will be made available by the authors, without undue reservation, to any qualified researcher.

\section{Ethics approval and consent to participate}


All procedures followed were in accordance with the ethical standards of the responsible committee on human experimentation (institutional and national) and with the Helsinki Declaration of 1975, as revised in 2000. This study was approved by the Ethics Committee of Beijing Shijitan Hospital, ethical approve No: sjtkyll-1x-2021(115). Informed consent was obtained from all patients for being included in the study.

\section{Consent for publication}

All authors agree to publish.

\section{Competing interest}

There are no conflicts of interest to declare.

\section{References}

1. Moatamed, N.A. Biobanking of Urine Samples: Methods and Protocols; Biobanking: 2019.

2. Jian, J.; Gao, Y. Urine biomarkers in the early stages of diseases: current status and perspective. Discovery Medicine 2018, 25, 57-65.

3. Wiggins, R.C.; Glatfelter, A.; Kshirsagar, B.; Brukman, J. Procoagulant activity in normal human urine associated with subcellular particles. Kidney International 1986, 29, 591-597.

4. Wang, M.; Zhou, L.; Yu, F.; Zhang, Y.; Li, P.; Wang, K. The functional roles of exosomal long non-coding RNAs in cancer. Cell Mol Life Sci 2019, 76, 2059-2076.

5. Tosar, J.P.; Witwer, K.; Cayota, A. Revisiting Extracellular RNA Release, Processing, and Function. Trends Biochem Sci 2021, 46, 438-445.

6. Guan, S.; Yu, H.; Yan, G.; Gao, M.; Sun, W.; Zhang, X. Size-dependent sub-proteome analysis of urinary exosomes. Anal Bioanal Chem 2019, 411, 4141-4149.

7. Bruschi, M.; Granata, S.; Santucci, L.; Candiano, G.; Fabris, A.; Antonucci, N.; Petretto, A.; Bartolucci, M.; Del Zotto, G.; Antonini, F.; et al. Proteomic Analysis of Urinary Microvesicles and Exosomes in Medullary Sponge Kidney Disease and Autosomal Dominant Polycystic Kidney Disease. Clin J Am Soc Nephrol 2019, 14, 834-843.

8. Dhondt, B.; Geeurickx, E.; Tulkens, J.; Van Deun, J.; Vergauwen, G.; Lippens, L.; Miinalainen, I.; Rappu, P.; Heino, J.; Ost, P.; et al. Unravelling the proteomic landscape of extracellular vesicles in prostate cancer by density-based fractionation of urine. J Extracell Vesicles 2020, 9, 1736935.

9. Nicholas, S.B. Use of urinary proteomics in diagnosis and monitoring of diabetic kidney disease. Lancet Diabetes Endocrinol 2020, 8, 261-262.

10. Tofte, N.; Lindhardt, M.; Adamova, K.; Bakker, S.J.L.; Beige, J.; Beulens, J.W.J.; Birkenfeld, A.L.; Currie, G.; Delles, C.; Dimos, I.; et al. Early detection of diabetic kidney disease by urinary proteomics and subsequent intervention with spironolactone to delay progression (PRIORITY): a prospective observational study and embedded randomised placebo-controlled trial. Lancet Diabetes Endocrinol 2020, 8, 301-312. 
11. Barreiro, K.; Dwivedi, O.P.; Leparc, G.; Rolser, M.; Delic, D.; Forsblom, C.; Groop, P.H.; Groop, L.; Huber, T.B.; Puhka, M.; et al. Comparison of urinary extracellular vesicle isolation methods for transcriptomic biomarker research in diabetic kidney disease. J Extracell Vesicles 2020, 10, e12038.

12. Helewski, K.; Konecki, J.; Kowalczyk, G. [Structural aspects of pulmonary gas exchange. II. Alveolar epithelium. Endothelium of capillaries of the alveolar wall]. Pneumonol Po/ 1989, 57, 253-259.

13. Erdbrügger, U.; Blijdorp, C.J.; Bijnsdorp, I.V.; Borràs, F.E.; Burger, D.; Bussolati, B.; Byrd, J.B.; Clayton, A.; Dear, J.W.; Falcón-Pérez, J.M.; et al. Urinary extracellular vesicles: A position paper by the Urine Task Force of the International Society for Extracellular Vesicles. J Extracell Vesicles 2021, 10, e12093.

14. Lötvall, J.; Hill, A.F.; Hochberg, F.; Buzás, E.I.; Di Vizio, D.; Gardiner, C.; Gho, Y.S.; Kurochkin, I.V.; Mathivanan, S.; Quesenberry, P.; et al. Minimal experimental requirements for definition of extracellular vesicles and their functions: a position statement from the International Society for Extracellular Vesicles. J Extracell Vesicles 2014, 3, 26913.

15. Nordin, J.Z.; Lee, Y.; Vader, P.; Mäger, I.; Johansson, H.J.; Heusermann, W.; Wiklander, O.P.; Hällbrink, M.; Seow, Y.; Bultema, J.J.; et al. Ultrafiltration with size-exclusion liquid chromatography for high yield isolation of extracellular vesicles preserving intact biophysical and functional properties. Nanomedicine 2015, 11, 879-883.

16. Dong, L.; Zieren, R.C.; Wang, Y.; de Reijke, T.M.; Xue, W.; Pienta, K.J. Recent advances in extracellular vesicle research for urological cancers: From technology to application. Biochim Biophys Acta Rev Cancer 2019, 1871, 342-360.

17. Hoshino, A.; Kim, H.S.; Bojmar, L.; Gyan, K.E.; Cioffi, M.; Hernandez, J.; Zambirinis, C.P.; Rodrigues, G.; Molina, H.; Heissel, S.; et al. Extracellular Vesicle and Particle Biomarkers Define Multiple Human Cancers. Cel/ 2020, 182, 1044-1061.e1018.

18. Pegtel, D.M.; Gould, S.J. Exosomes. Annu Rev Biochem 2019, 88, 487-514.

19. Kugeratski, F.G.; Hodge, K.; Lilla, S.; McAndrews, K.M.; Zhou, X.; Hwang, R.F.; Zanivan, S.; Kalluri, R. Quantitative proteomics identifies the core proteome of exosomes with syntenin-1 as the highest abundant protein and a putative universal biomarker. Nat Cell Bio/ 2021, 23, 631-641.

20. Nachury, M.V.; Seeley, E.S.; Jin, H. Trafficking to the ciliary membrane: how to get across the periciliary diffusion barrier? Annu Rev Cell Dev Biol 2010, 26, 59-87.

21. Kiral, F.R.; Kohrs, F.E.; Jin, E.J.; Hiesinger, P.R. Rab GTPases and Membrane Trafficking in Neurodegeneration. Curr Bio/ 2018, 28, R471-r486.

22. Shan, M.M.; Sun, S.C. The multiple roles of RAB GTPases in female and male meiosis. Hum Reprod Update 2021, 27, 1013-1029.

23. Bryant, D.M.; Datta, A.; Rodríguez-Fraticelli, A.E.; Peränen, J.; Martín-Belmonte, F.; Mostov, K.E. A molecular network for de novo generation of the apical surface and lumen. Nat Cell Bio/ 2010, 12, 1035-1045.

24. Lai, Y.C.; Kondapalli, C.; Lehneck, R.; Procter, J.B.; Dill, B.D.; Woodroof, H.I.; Gourlay, R.; Peggie, M.; Macartney, T.J.; Corti, O.; et al. Phosphoproteomic screening identifies Rab GTPases as novel downstream targets of PINK1. Embo j 2015, 34, 2840-2861. 
25. Nassari, S.; Del Olmo, T.; Jean, S. Rabs in Signaling and Embryonic Development. Int J Mol Sci 2020, 21.

26. Schlüter, O.M.; Schmitz, F.; Jahn, R.; Rosenmund, C.; Südhof, T.C. A complete genetic analysis of neuronal Rab3 function. J Neurosci 2004, 24, 6629-6637.

27. Kim, J.D.; Chun, A.Y.; Mangan, R.J.; Brown, G.; Mourao Pacheco, B.; Doyle, H.; Leonard, A.; El Bejjani, R. A conserved retromer-independent function for RAB-6.2 in C. elegans epidermis integrity. J Cell Sci 2019, 132.

28. Sato, T.; Iwano, T.; Kunii, M.; Matsuda, S.; Mizuguchi, R.; Jung, Y.; Hagiwara, H.; Yoshihara, Y.; Yuzaki, M.; Harada, R.; et al. Rab8a and Rab8b are essential for several apical transport pathways but insufficient for ciliogenesis. J Cell Sci 2014, 127, 422-431.

29. Lv, P.; Sheng, Y.; Zhao, Z.; Zhao, W.; Gu, L.; Xu, T.; Song, E. Targeted disruption of Rab10 causes early embryonic lethality. Protein Cell 2015, 6, 463-467.

30. Hildebrandt, F.; Benzing, T.; Katsanis, N. Ciliopathies. N Engl J Med 2011, 364, 1533-1543.

31. Yoshimura, S.; Egerer, J.; Fuchs, E.; Haas, A.K.; Barr, F.A. Functional dissection of Rab GTPases involved in primary cilium formation. J Cell Bio/ 2007, 178, 363-369.

32. Ishikawa, H.; Marshall, W.F. Ciliogenesis: building the cell's antenna. Nat Rev Mol Cell Biol 2011, 12, 222-234.

33. Reales, E.; Bernabé-Rubio, M.; Casares-Arias, J.; Rentero, C.; Fernández-Barrera, J.; Rangel, L.; Correas, I.; Enrich, C.; Andrés, G.; Alonso, M.A. The MAL protein is crucial for proper membrane condensation at the ciliary base, which is required for primary cilium elongation. J Cell Sci 2015, 128, 2261-2270.

34. Ao, X.; Zou, L.; Wu, Y. Regulation of autophagy by the Rab GTPase network. Cell Death Differ 2014, $21,348-358$.

35. Zhang, J.; Zhang, X.; Liu, G.; Chang, D.; Liang, X.; Zhu, X.; Tao, W.; Mei, L. Intracellular Trafficking Network of Protein Nanocapsules: Endocytosis, Exocytosis and Autophagy. Theranostics 2016, 6, 2099-2113.

36. Ciura, S.; Sellier, C.; Campanari, M.L.; Charlet-Berguerand, N.; Kabashi, E. The most prevalent genetic cause of ALS-FTD, C9orf72 synergizes the toxicity of ATXN2 intermediate polyglutamine repeats through the autophagy pathway. Autophagy 2016, 12, 1406-1408.

37. He, Z.; Wang, K.C.; Koprivica, V.; Ming, G.; Song, H.J. Knowing how to navigate: mechanisms of semaphorin signaling in the nervous system. SCi STKE 2002, 2002, re1.

38. Van Battum, E.; Heitz-Marchaland, C.; Zagar, Y.; Fouquet, S.; Kuner, R.; Chédotal, A. Plexin-B2 controls the timing of differentiation and the motility of cerebellar granule neurons. Elife 2021, 10.

39. Bonilha, C.S.; Benson, R.A.; Brewer, J.M.; Garside, P. Targeting Opposing Immunological Roles of the Junctional Adhesion Molecule-A in Autoimmunity and Cancer. Front Immunol 2020, 11, 602094.

40. Chen, B.H.; Chang, Y.J.; Lin, S.; Yang, W.Y. Hsc70/Stub1 promotes the removal of individual oxidatively stressed peroxisomes. Nat Commun 2020, 11, 5267. 
Figures

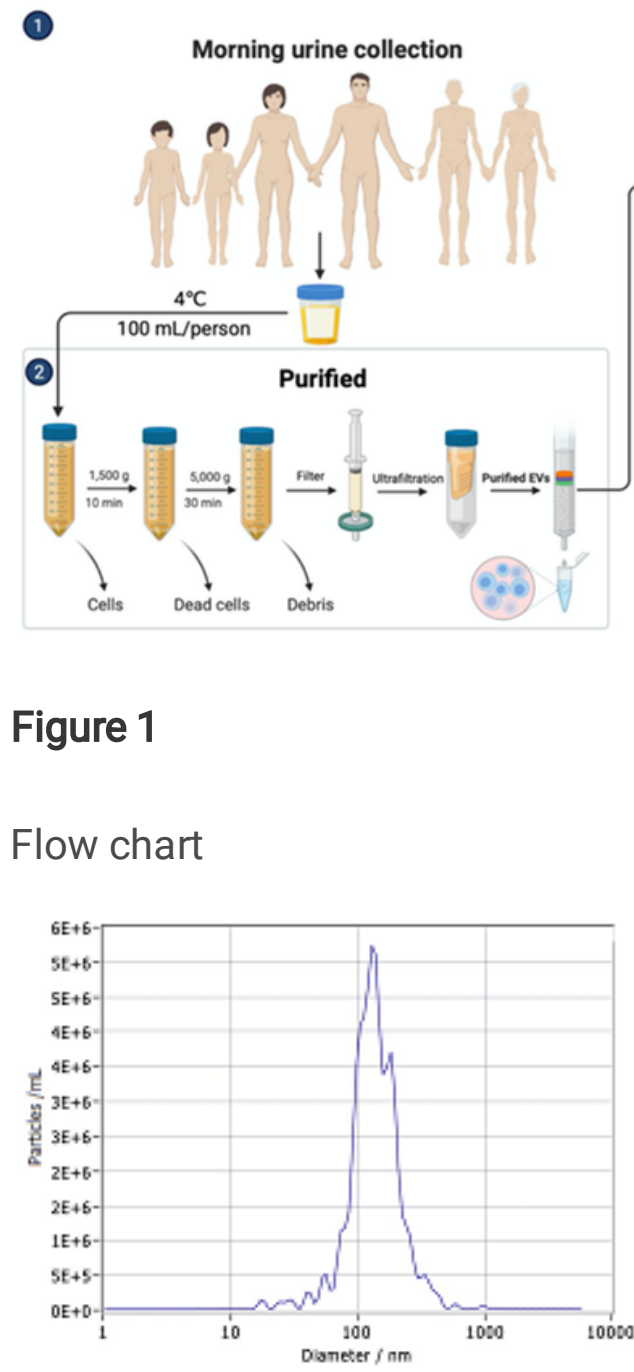

\section{Figure 1}

\section{Flow chart}

( a)

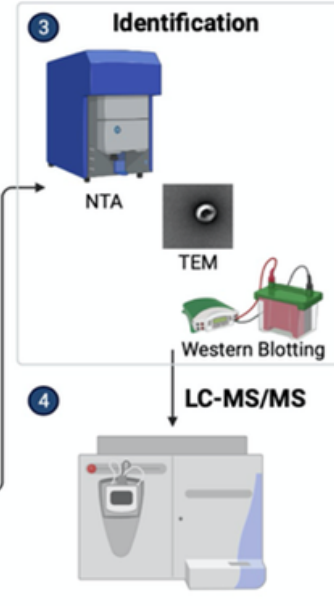

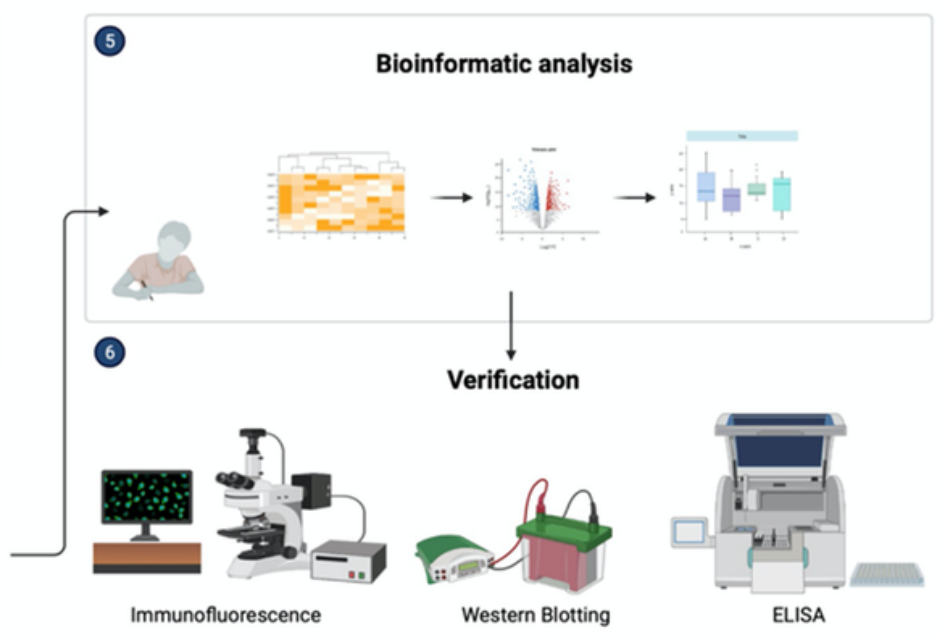

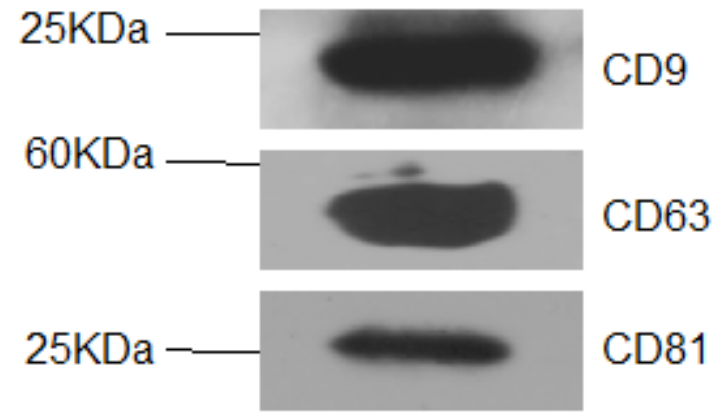

( b)
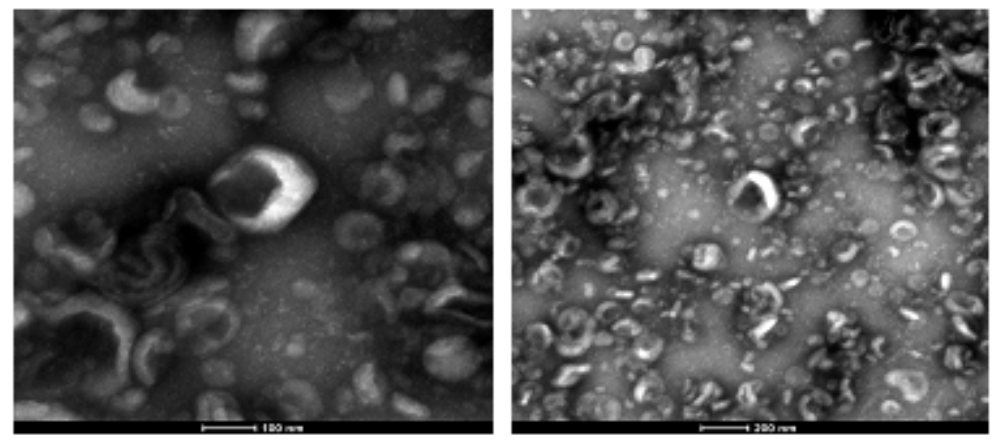

(c)

Figure 2

Exosome identification 


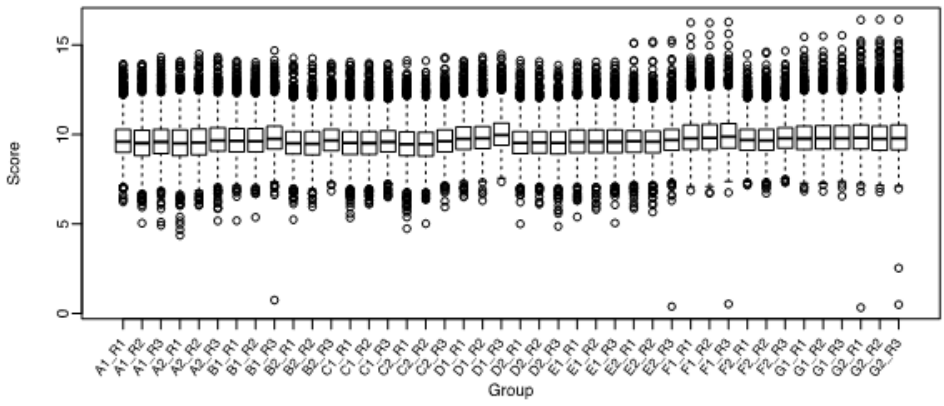

( a )

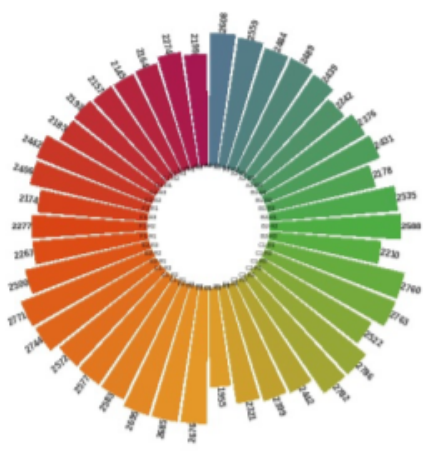

(c)

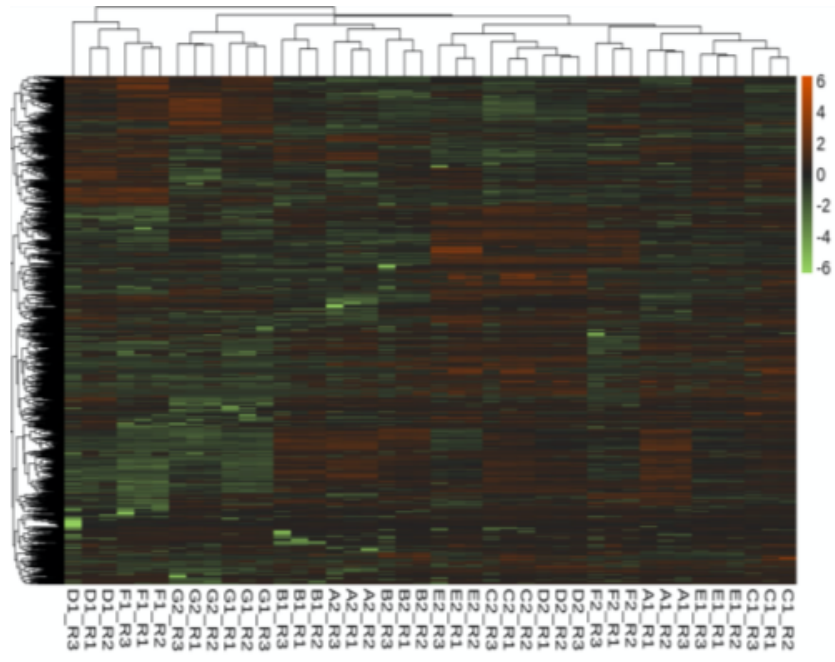

( b )

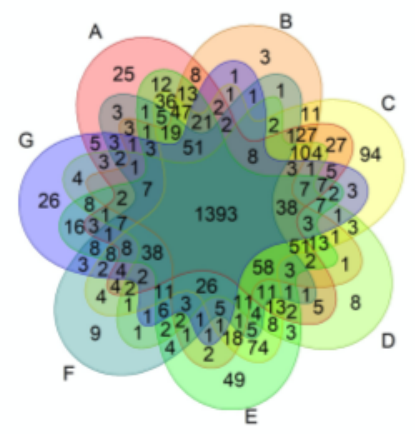

(d)

\section{Figure 3}

Quantitative proteomics analysis of urine exosomes. (a) BoxPlot: Box diagram obtained from quantitative protein in groups A-G. (b) Heatmap: Cluster analysis of overall proteins expression in groups A-G. (c) NightingaleRose: The number of proteins obtained from the A-G groups three times on the computer. (d) Venn diagram: All age stages shared 1,393 proteins.
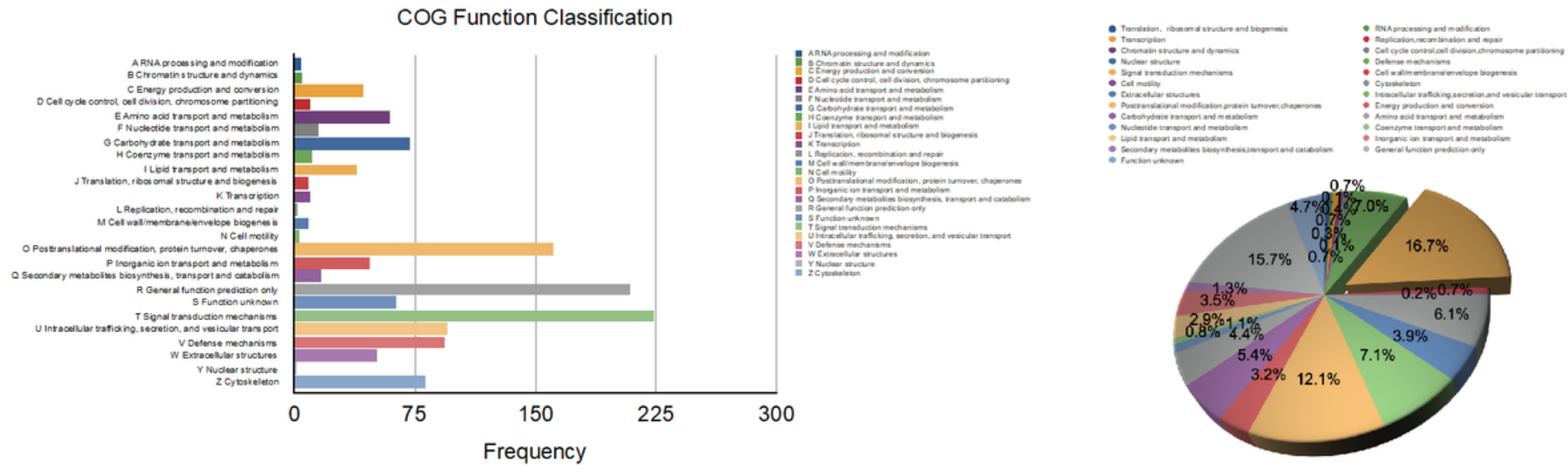

Figure 4 
COG function classification of 1,393 urinary exosomes co-expressed proteins in groups A-G and its statistical pie chart.

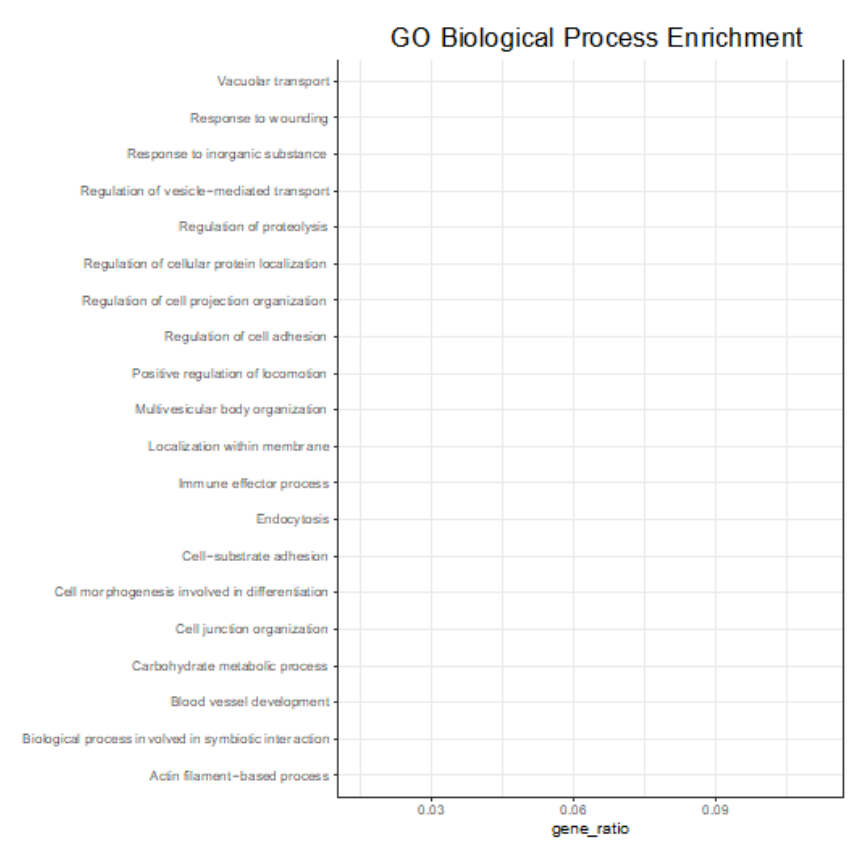

( a)

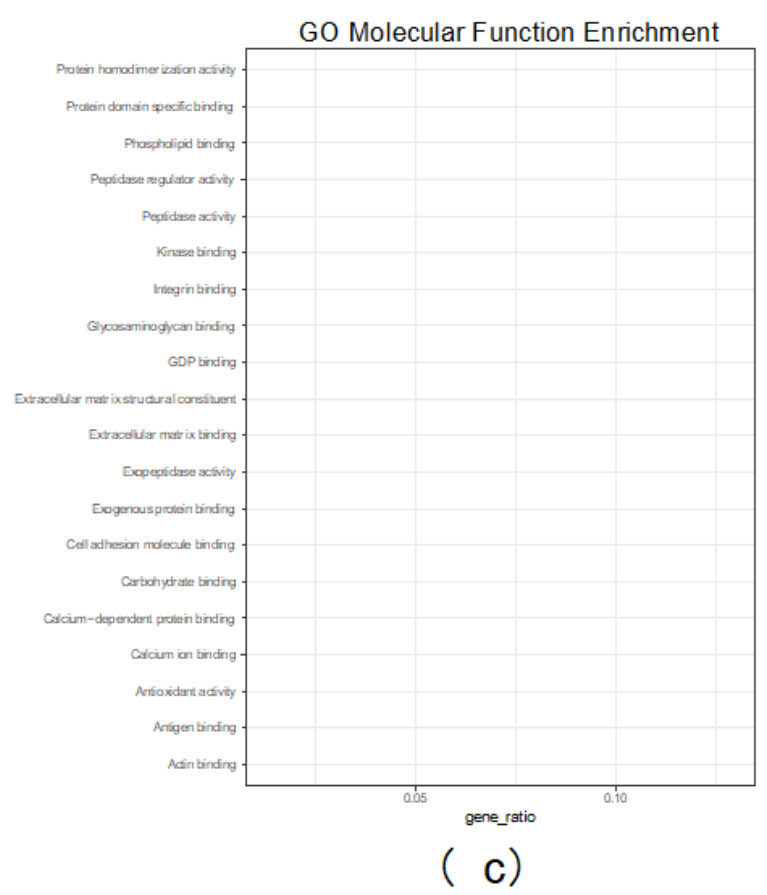

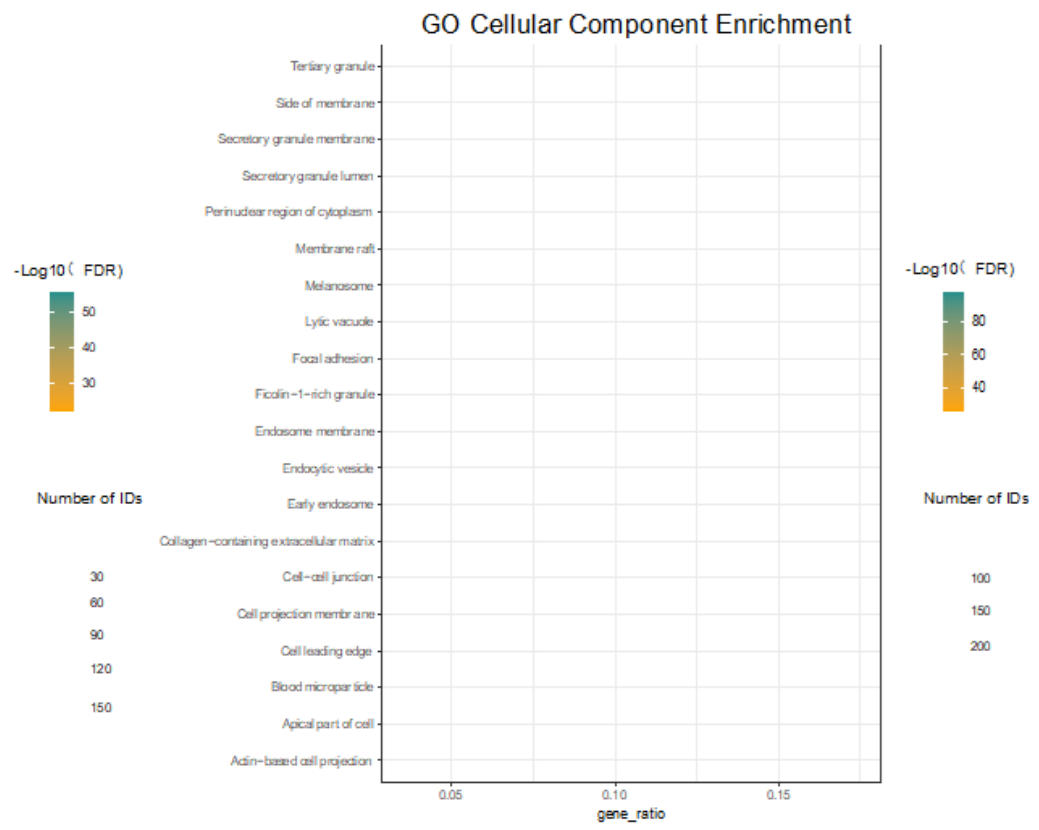

( b)

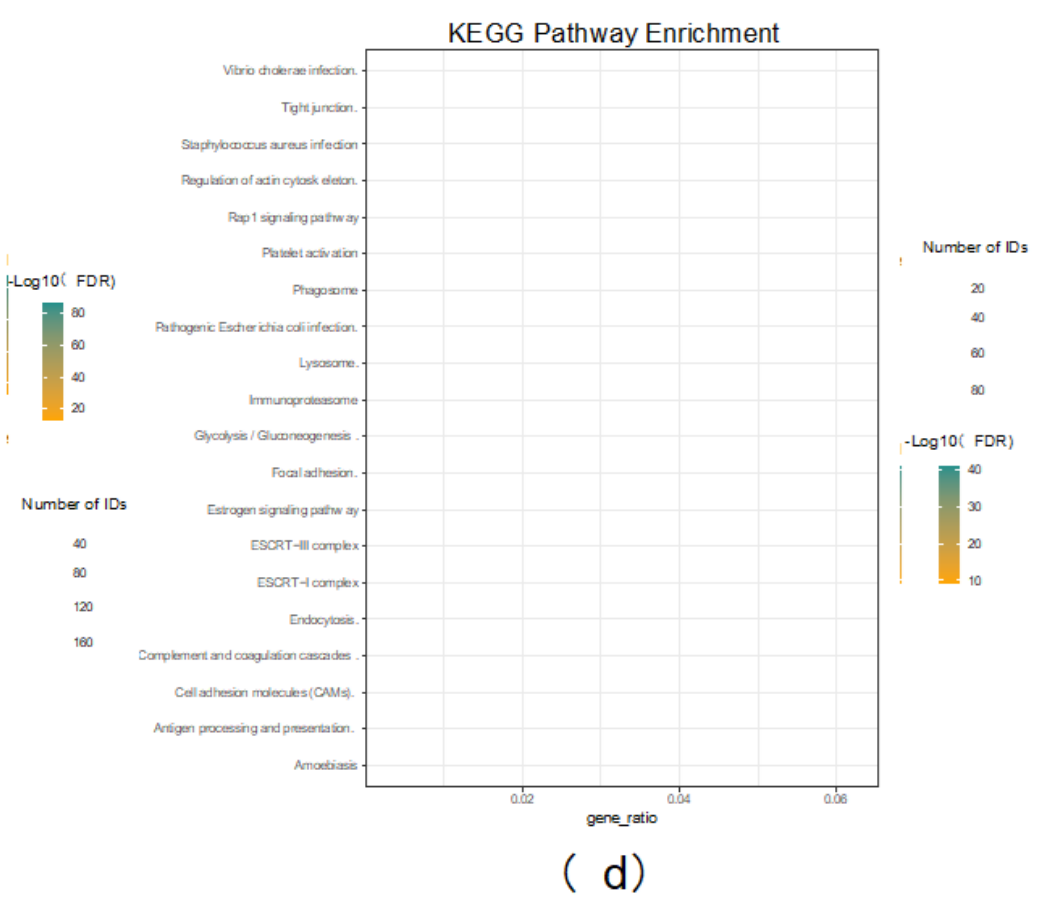

\section{Figure 5}

GO analysis of 1,393 co-expressed proteins: (a) Bubble chart of the BP enrichment analysis of 1,393 coexpressed proteins in human urine exosomes. (b) Bubble chart of the CC enrichment analysis of 1,393 coexpressed proteins in human urine exosomes. (c) Bubble chart of MF enrichment analysis of 1,393 coexpressed proteins in human urine exosomes. (d) Bubble chart of KEGG analysis of human urine exosome 1,393 co-expression proteins. 


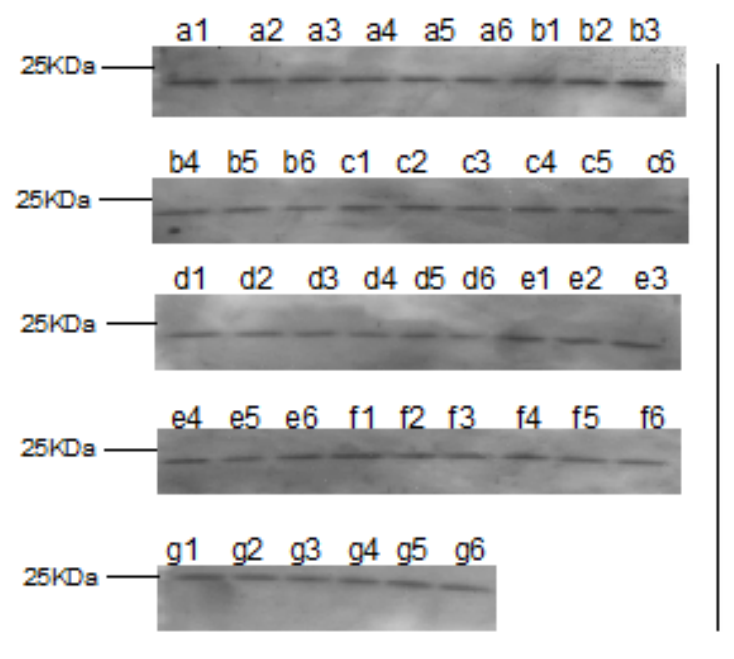

(a)

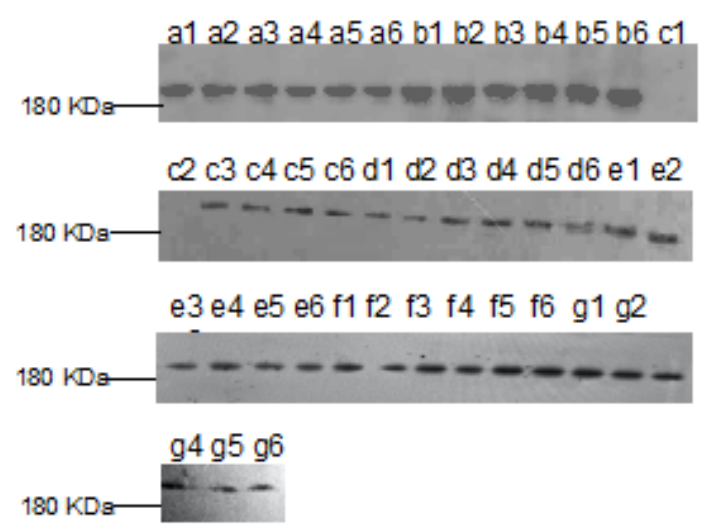

(c)

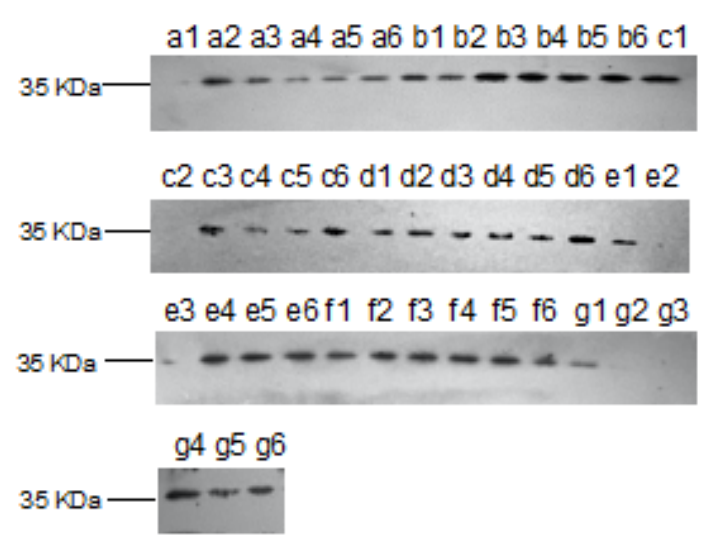

(e)

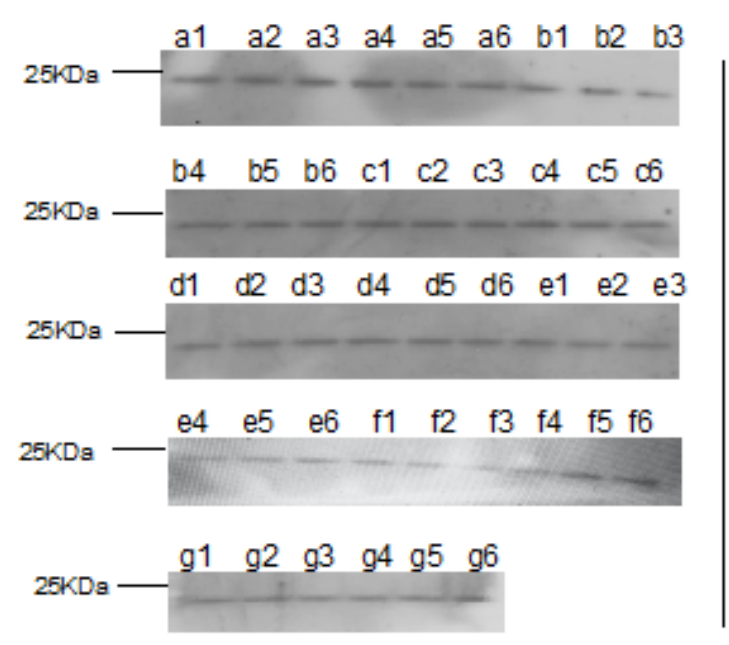

RAB8B

(b)

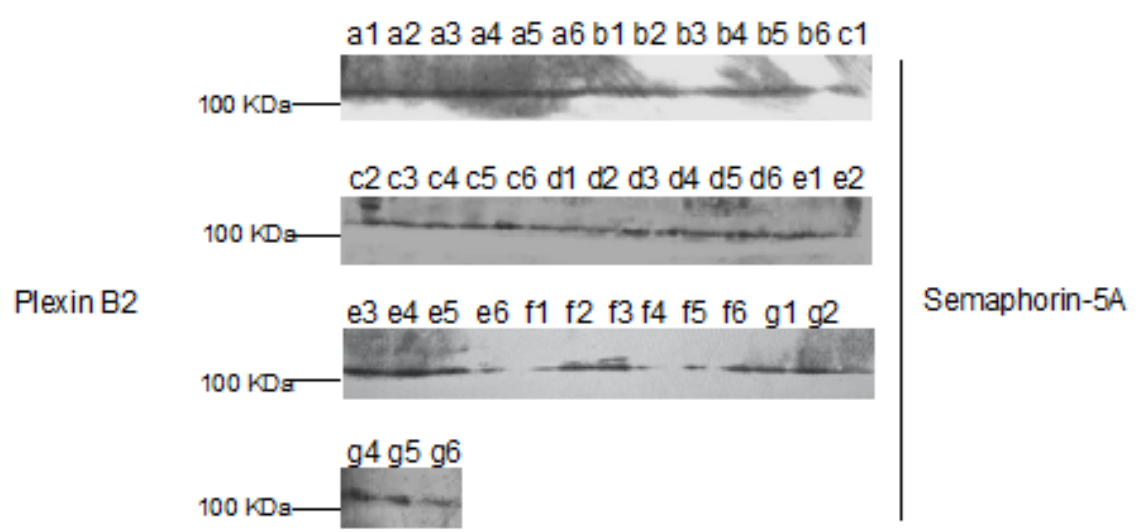

(d)

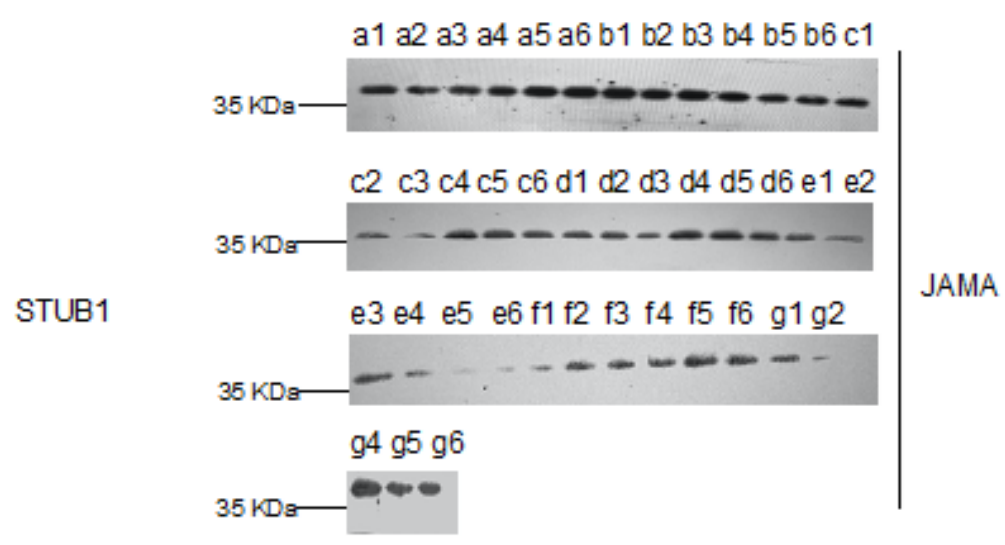

(f)

\section{Figure 6}

The verification of RAB8A, RAB8B, Semaphorin-5A, Plexin B2, STUB1, JAMA by Western blot. (a) Western blot verified the expression of RAB8A in the A-G groups, with 6 people in each group, 1-3 for female samples, and 4-6 for male samples. (b) Western blot verified the expression of RAB8B. (c) Western blot verified the expression of Plexin B2. (d) Western blot verified the expression of Semaphorin-5A. (e) Western blot verified the expression of STUB1. (f) Western blot verified the expression of JAMA. 

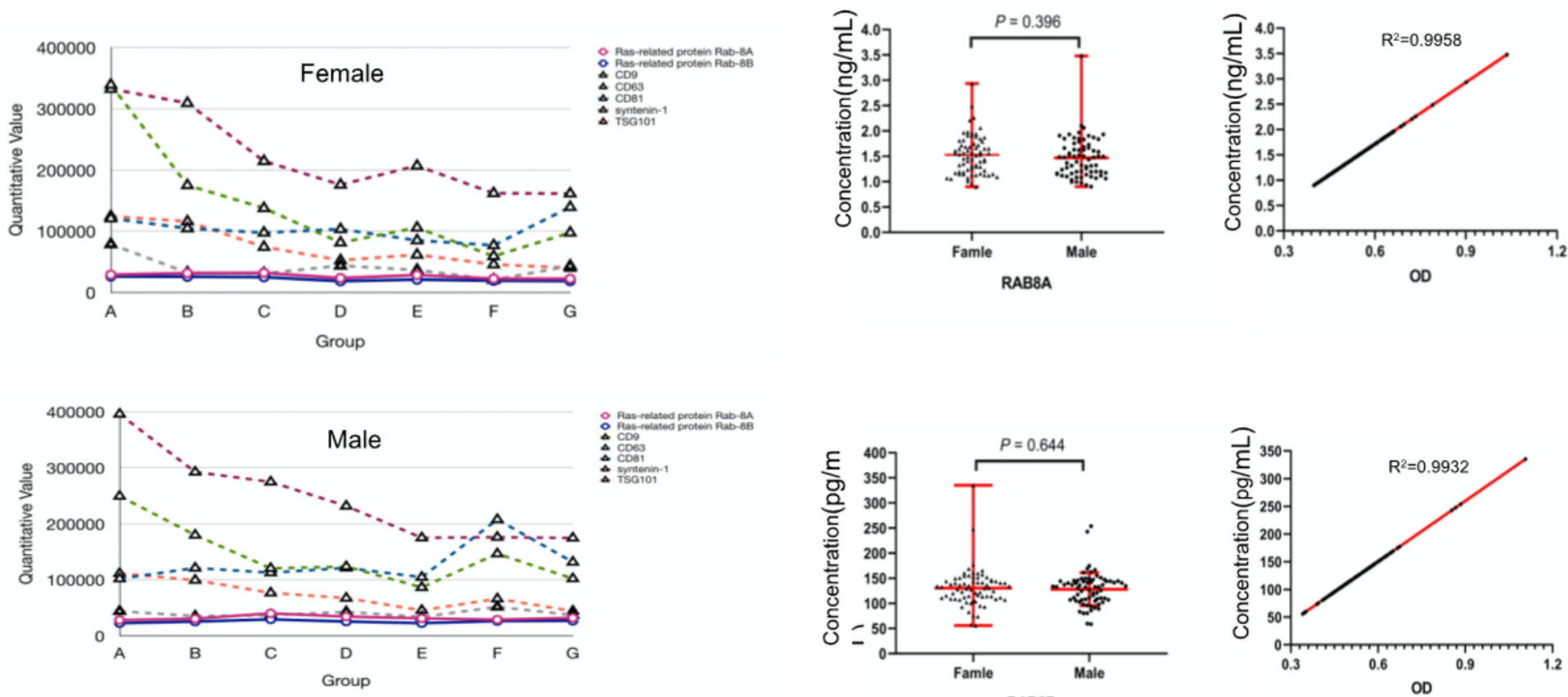

( a )
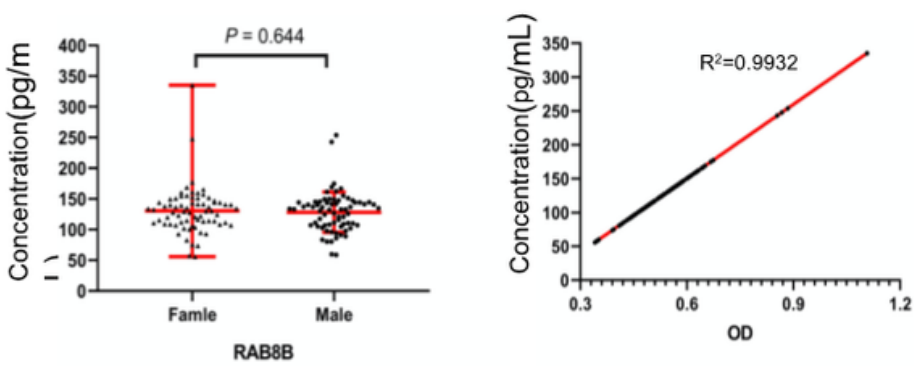

(b)
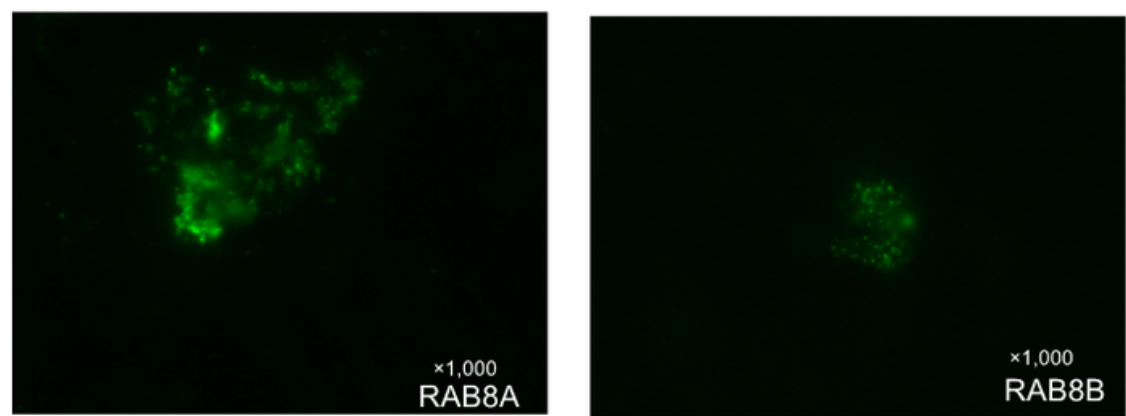

( c )

\section{Figure 7}

The verification of RAB8A and RAB8B. (a) The expression of RAB8A/RAB8B in the female and male populations. (b) ELISA determined the concentration of RAB8A/8B. (c) The expression of RAB8A/8B was determined by immunofluorescence. 